\title{
The corticosterone-glucocorticoid receptor- AP1/CREB axis inhibits luteinizing hormone receptor expression in mouse granulosa cells
}

\section{Yinghui Wei}

Nanjing Agricultural University

Ming Shen ( $\nabla$ shenm2015@njau.edu.cn )

Nanjing Agricultural University

\section{Research}

Keywords: stress, corticosterone, granulosa cells, luteinizing hormone receptor, glucocorticoid receptor

Posted Date: June 4th, 2020

DOI: https://doi.org/10.21203/rs.3.rs-30613/v1

License: (c) (1) This work is licensed under a Creative Commons Attribution 4.0 International License.

Read Full License 


\section{Abstract \\ Background}

Under stress conditions, luteinizing hormone (LH)-mediated ovulation is inhibited, resulting in insufficient oocyte production and excretion during follicular development. When the body is stressed, a large amount of corticosterone (CORT) is generated, which will lead to disorder of the body's endocrine system and damage to the body. Our previous work showed that corticosterone can block follicular development in mice. Since LH acts through binding with the LH receptor (LHR), the present study aimed to investigate whether and how CORT influence luteinizing hormone receptor expression in mouse ovarian granulosa cells (GCs).

\section{Methods}

For this purpose, 3-week-old ICR female mice were injected intraperitoneally with pregnant horse serum gonadotropin (PMSG). Meanwhile, the treatment group were injected with corticosterone corticosterone ( $1 \mathrm{mg} /$ mouse) at intervals of $8 \mathrm{~h}$; while the control group was injected with same volume of methyl sulfoxide (DMSO). Granulosa cells were collected at $24 \mathrm{~h}, 48 \mathrm{~h}$, and $55 \mathrm{~h}$ after PMSG injection. For in vitro experiments, mice granulosa cells obtained from healthy follicles were treated with corticosterone alone, or together with inhibitors against glucocorticoid receptor (GR).

\section{Results}

The results showed that corticosterone caused down-regulation of luteinizing hormone receptor expression in granulosa cells, which was accompanied by impaired cell viability. Moreover, the effects of corticosterone was mediated by binding to its receptor in granulosa cells. Further investigations revealed that glucocorticoid receptor might regulated the transcription of luteinizing hormone receptor through inhibiting the expression of luteinizing hormone receptor transcription factors, including AP1 and CREB.

\section{Conclusions}

Our findings suggested a possible mechanism of corticosterone-induced anovulation involving the inhibition of luteinizing hormone receptor expression in granulosa cells by corticosterone-glucocorticoid receptor-AP1 / CREB axis.

\section{Introduction}

Luteinizing hormone $(\mathrm{LH})$ is a glycoprotein hormone secreted by the anterior pituitary gland in response to the hypothalamic gonadotropin-releasing hormone [1]. LH receptor (LHR) is a key hormone receptor that induces ovulation and luteal formation. After binding with LH in granulosa cells (GCs), LHR induces 
the growth of follicles from primary follicles into preovulatory follicles. The expression of LHR undergoes dynamic changes in the normal ovarian cycle. Initially, LHR is expressed in follicular membrane cells before secondary follicles [2]. With the synergistic effect of FSH, estradiol and other paracrine factors, LHR expression levels increase in GCs during follicular growth and reach a maximum level before ovulation [3-5]. The combining of LH with LHR in GCs activating the AC / CAMP / PKA, PI3K / AKT, and RAS signaling, which are essential for ovulation [6]. The transcription of LHR is regulated by a variety of transcription factors,such as CREB and AP1. They are two well-described transcription factors which serve important roles in ovarian functions [7].The AP1 transcription factor usually expresses its activity as a homodimer or heterodimer of c-Jun and c-Fos. CREB is a ubiquitous transcription factor that controls cell proliferation and survival. When the LHR in GCs was knocked out, even with high-dose of FSH stimulation, follicular development could not be restored during the follicular phase. Therefore, the expression of LHR in ovarian GCs is essential for follicle maturation and ovulation $[8,9]$.

Upon stress response, the hypothalamus-pituitary-adrenal (HPA) axis is activated and glucocorticoid levels increase rapidly. Increased glucocorticoid content can disturb the endocrine system, suppress the immune system, damage the reproductive system and cause reproductive disorders $[10,11]$. Cortisol (in human and mammal) and corticosterone (in rodents) is the main component of glucocorticoids. There is evidence that the activation of the HPA axis under stress conditions induce a surge of cortisol/corticosterone (referred to as CORT), which will reduce the pulse secretion of $\mathrm{GnRH} / \mathrm{LH}$, leading to impaired ovulation due to the devoid of LH support [12]. During the follicular phase of the ewe, high concentrations of CORT inhibit the frequency of LH secretion, resulting in low fertility [13]. Early laboratory experiments have shown that mice in estrus suffered from decreased ovulation due to increased CORT levels in the body [14]. Moreover, there is evidence showing that LHR expression was reduced during stress stimulation [15]. Actually, the role of glucocorticoids under stress is mediated by the pituitary glucocorticoid receptor (GR) $[16,17]$. GR belongs to the nuclear receptor family and acts as a transcription regulator [18]. Once activated, GR translocates to the nucleus and interferes with the transcription of downstream genes [19]. However, whether CORT can regulate the expression of LHR in ovarian GCs through GR remains to be studied.

Since there are many stress factors in the process of animal reproduction, it is difficult to directly study the correlation between stressors and ovarian functions. Our previous experiments have confirmed that continuous injection of CORT can be used to build a mouse stress model. However, the underlying mechanism of CORT-mediated suppression of follicular development remains to be investigated. In this study, we explored whether and how CORT affects the expression of LHR in ovarian GCs. Our findings might lay a theoretical foundation for developing protocols used in alleviating the adverse effects of various stressors on animal reproduction.

\section{Materials And Methods}

\section{Chemicals and antibodies}


PBS was purchased from HyClone Laboratories, Inc. (Logan, UT). Pregnant mare serum gonadotropin (PMSG) was purchased from Ningbo Second Hormone Factory (Ningbo, Zhejiang, China). CORT, T-5224, 666 - 15 were from MCE (New Jersey, U.S.A). Dimethyl sulfoxide (DMSO) was purchased from SigmaAldrich (St.Louis, MO). Anti-LHR was from Abclone (Wuhan, China). Antibodies against C-Jun(9165), cFos(2250), Phospho-CREB (9197), CREB (9198) were purchasedfrom Cell Signaling Technology (Beverly, MA).

\section{Induction of stress in vivo}

All the animal experiments were performed in accordance with the guidelines of the Animal Research Institute Committee at Nanjing Agricultural University. Three-to-four-week-old female ICR (Institute of Cancer Research) mice (Qing Long Shan Co., Animal Breeding Center, Nanjing, China) were housed five per cage in a temperature-controlled $\left(22 \pm 2{ }^{\circ} \mathrm{C}\right)$ room with a $12: 12 \mathrm{~h}$ light:dark cycle and had ad libitum access to water and food. The mice (three-to-four-week-old) were randomly divided into control group and CORT group. Each mouse in the treatment group was injected with CORT. CORT was dissolved in DMSO to reach a concentration of $0.2 \mathrm{mg} / \mu \mathrm{L}[14,20]$. The control group was injected with the same volume of DMSO. The treatment procedures were briefly presented as follows: On the first day at 7:00 a.m., mice were injected with $10 \mathrm{IU}$ of PMSG. The control group and the treatment group were injected with $5 \mu \mathrm{L}$ of DMSO and $5 \mu \mathrm{L}$ of CORT $(0.2 \mathrm{mg} / \mu \mathrm{L})$ respectively every $8 \mathrm{~h}$. At $24 \mathrm{~h}, 48 \mathrm{~h}, 55 \mathrm{~h}$ after the PMSG injection, mice in each group were sacrificed for collection of GCs.

\section{Cell culture and treatments}

Primary GCs were isolated from ovarian follicles and observed the growth of the cells $24 \mathrm{~h}$ after inoculation. When the cell plate inoculation area reaches $80 \%-90 \%$ (about 3 days after inoculation), consequently various drug treatment experiments can be performed. [21-23]. For drug administration, GCs were incubated with $100 \mu \mathrm{M}, 200 \mu \mathrm{M}$, or $300 \mu \mathrm{M}$ CORT for 12 hours. In some experiments, GC was pretreated with T5224 $(75 \mu \mathrm{M})$ or $666-15(7.5 \mu \mathrm{M}))$ for $2 \mathrm{~h}$, and then treated with CORT for $12 \mathrm{~h}$.

\section{Cell viability assay}

Cell viability was assessed by measuring the conversion of tetrazolium salt (WST-8) to formazan according to the manufacturer's instructions of Cell Counting Kit-8 (CCK-8, Dojindo Laboratories, Kumamoto, Japan). Briefly, cells seeded in 96 -well plates were grown to $90 \%$ confluency (equaling $5 \times 10^{4}$ cells/well) following 2 days of culture. The GC was exposed to CORT $(100 \mu \mathrm{M}, 200 \mu \mathrm{M}$, or $300 \mu \mathrm{M})$ or DMSO (control) for $12 \mathrm{~h}$. After treatment, $10 \mu \mathrm{L}$ of CCK-8 solution were added to each well containing 100 $\mu \mathrm{L}$ medium and incubated for an additional $3 \mathrm{~h}$ at $37^{\circ} \mathrm{C}$. Cell viability was then determined by reading the optical density at $450 \mathrm{~nm}$ using a microplate reader (Thermo Fisher Scientific, San Jose, CA).

\section{Western blotting}

Western blotting was performed as described previously[20). Briefly, total protein extracts were fractioned by electrophoresis on a 4-20\% Sure PAGE gel (Genscript, Nanjing, China) and transferred to PVDF membranes (Millipore, Bedford, MA) by electroblotting. Nonspecific binding sites were blocked with $5 \%$ 
bovine serum albumin in TBST (Solarbio, Beijing, China) for $1 \mathrm{~h}$. The membranes were then incubated with primary antibodies $(1: 1000)$ containing $0.25 \%$ bovine serum albumin in TBST overnight at $4{ }^{\circ} \mathrm{C}$. After washing in TBST three times, the membranes were incubated at room temperature for $1 \mathrm{~h}$ with a diluted (1:2000) secondary antibody against rabbit (ab6721, Abcam, Cambridge, UK). Signal detection was performed using the SuperSignal West Pico chemiluminescent substrate (Pierce, Rockford, IL). The expression values of target proteins were normalized to GAPDH as the loading control.

\section{Quantitative RT-PCR (qRT-PCR)}

The collection of total RNA and cDNA from GCs were performed as described previously [24]. The qRTPCR was carried out using SYBR Premix Ex Taq (Takara, DRR420A) in a StepOnePlus ${ }^{\text {TM }}$ Real-Time PCR System (Applied Biosystems, Foster City, CA, USA). The primer sequences for the target genes are listed in Table 1. Glyceraldehyde 3-phosphate dehydrogenase (GAPDH) was used as an internal control. The relative expression was analyzed by the method.

Table 1

Primers used in present study

\begin{tabular}{l|lll|}
\hline Primer & Forward sequence & Reverse sequence \\
\hline LHR & 5'-GCTGACCTACCCTAGCCACT-3' & 5'-CAGAGTGATGAAGCGTCTCGT-3' \\
\hline CREB & 5'-TGTACCACCGGTATCCATGC-3' & 5'-TGGATAACGCCATGGACCTG-3' \\
\hline C-Jun & 5'-GGCACATCACCACTACACCG-3' & 5'-GTTCTGGCTATGCAGTTCAGC-3' \\
\hline c-Fos & 5'-GTGAAGACCGTGTCAGGAGG-3' & 5'-GATCTGTCTCCGCTTGGAGT-3' \\
\hline GR & 5'-AGTCAAGGTTTCTGCGT-3' & 5'-CCATCACTTTTGTTTCG-3' \\
\hline GAPDH & 5'-AAGGTGGTGAAGCAGGCAT-3' & 5'-GGTCCAGGGTTTCTTACTCCT - 3' \\
\hline
\end{tabular}

Statistical significance was determined using the SPSS software version 20.0 (SPSS). Experiments were repeated at least three times. Data were presented as mean \pm S.E. All data was evaluated by Kolmogorove-Smirnov test to confirm their distribution. The statistical significance between groups was analyzed using oneway ANOVA, and $P$ values less than 0.05 were considered to be statistically significant.

\section{Results}

\section{CORT inhibits LH receptor expression in ovarian granulosa cells of mice}

Under stress conditions, the HPA axis is activated, leading to the release of CORT, which can cause decreased ovulation. Since LH-induced ovulation requires the binding of LH with the LH receptor (LHR) in 
ovarian granulosa cells (GCs), we thus examined whether CORT might influence the expression of LHR in GCs collected form mice with continuous injection of CORT. We continue to inject CORT at the same high dose level to ensure that the mice are under stress and that the content of CORT is not disturbed by day and night conditions. As shown in Fig. 1A-C, with the development of follicles, the expression of LHR increased continuously, the protein and mRNA levels of LHR in GCs of the control group were significant at $55 \mathrm{~h}(\mathrm{P}<0.01)$. In contrast, LHR expression was inhibited by CORT injection during follicular growth. Particularly, at $55 \mathrm{~h}$ after PMSG injection, both protein and mRNA levels of LHR in CORT group were significantly lower $(P<0.01)$ than those of the control group.

We next determined the effects of CORT in cultured GCs. Consistent with the in vivo results, CORT inhibited the LHR mRNA levels in a dose-dependent manner (Fig. 1D). GCs treated with $200 \mu \mathrm{M}$ CORT also showed a significant decrease in LHR protein level (Fig. 1E and F). Moreover, a loss of cell viability was observed in GCs with CORT treatment (Fig. 1G).

\section{CORT-mediated inhibition of LHR expression is dependent on the activation of glucocorticoid receptor in mouse ovarian GCs}

The physiological functions of CORT were conducted by activating downstrean signaling transduction through binding with the glucocorticoid receptor (GR) [25]. Therefore, we evaluated whether GR is involved in CORT-mediated regulation of LHR expression in mouse GCs. As shown in Fig. 2A-C, compared with the control group, mice injected with CORT exihibited significantly higher expression of GR in ovarian GCs. In accordance with this, CORT treatment of primary GCs in vitro also showed marked upregulation of GR (Fig. 2D-F).

To further clarify whether CORT regulates LHR expression by activating the GR pathway, we treated GCs with the GR inhibitor RU486. The results of Fig. 3A-C showed that, RU486 eliminated the inhibitory effects of CORT on LHR expression at both protein and transcription levels.

\section{CORT inhibits the transcriptional activity of LHR transcription factors in GCs}

LH binds to its G protein-coupled receptor LHR and initiates the classic AC / cAMP / PKA pathway, resulting in phosphorylation and activation of the transcription factor CREB. The activated CREB can act as a transcription enhancer to stimulate gene transcription and upregulate LHR expression. The promoter of the LHR gene also includes a binding site for AP1. It has been reported that AP1 binding sites are essential for activating cAMP-induced LHR transcription [1].The active form of AP1 consists of c-Jun and c-Fos, which can dimerize to form the AP1 complex. To further elucidate the underlying mechanism of CORT-mediated inhibition of LHR expression in GCs, we collected GCs at $55 \mathrm{~h}$ after PMSG injection and analyzed the expression of CREB and AP1, by Western blot and qRT-PCR. As shown in Fig. 4A-G, CORT 
reduced the levels of total CREB and phosphorylated CREB (Ser133), and down-regulated the expression of AP1 subunits (including c-Fos and c-Jun).

We next determined expression of AP1 subunits and CREB in cultured GCs. In agreement with the in vivo results, primary GCs treated with CORT showed decreased levels of CREB, phosphorylated CREB (Ser133), c-Fos, and c-Jun (Fig. 5A-E). To assess whether LHR down-regulation is related to CORT-induced suppression of CREB and AP1. We used 666-15 (CREB-specific inhibitor) and T-5224 (AP1-specific inhibitors) to inhibit CREB and AP1 activity respectively. As shown in Fig. 5F-G, LHR protein and mRNA levels are down-regulated when inhibitors were used.

\section{The expression of AP1 and CREB is regulated by GR}

GR can affect the function and recruitment of transcription factors [26]. After combining with CORT, GR is transferred to the nucleus to interact with GREs, thereby regulating the expression of target genes $[27,28]$. To further clarify the signaling cascades linking CORT, GR, and LHR expression, we treated mice GCs with a CORT inhibitor RU486, and analyzed expression of GR, AP1, and CREB using qRT-PCR or Western blot. As shown in Fig. 6A-G, the CORT inhibitor RU486 successfully eliminated the inhibitory effects of CORT on AP1 and CREB expression.

\section{Discussion}

During stress conditions, the activation of the HPA axis increases the plasmic content of glucocorticoids, which inhibit the synthesis and release of reproductive hormones [29,30], leading to impaired follicular development and decreased ovulation in female animals [31]. LH is the key gonadotrophin that promotes ovulation. In the normal estrous cycle, the pituitary gland will secrete $\mathrm{LH}$, which functions by binding to its receptor LHR in the ovary [32]. Studies have shown that when glucocorticoid exceeds the normal level, it will work through GR, which acts as a nuclear transcription factor to regulate the transcription of target genes. As the main component of glucocorticoids, CORT was recognized to negatively affect the ovulation process in our previous studies, although the underlying mechanism remains unclear. Here, we demonstrated that continuous intraperitoneal injection of CORT on mice downregulates LHR expression in ovarian GCs. In addition, our findings showed for the first time that CORT inhibits LHR expression by activating the GR-CREB/AP1 axis.

\section{Impact of CORT on LHR expression}

During the process of follicular dominance, the level of LHR is gradually increased. At the end of the follicular phase, the surge of LH,stimulates ovulation by binding to LHR in ovarian GCs [33]. The decrease of LHR expression in GCs causes ovulation failure due to insufficient LH stimulation [34, 35]. Although CORT has been reported to inhibit ovulation, it is still unclear whether CORT might directly regulate the expression of LHR in GCs. In this study, we demonstrated that continuous intraperitoneal injection of CORT into mice reduced LHR expression in GCs collected from developing follicles, especially the 
preovulatory follicles, indicating that CORT might impede ovulation in females by inhibiting LHR expression in GCs. On the other hand, studies have shown that stress-induced CORT accumulation can inhibit GnRH secretion and reduce LH levels [36]. It is conceivable that the downregulation of gonadotropins levels might affect GCs survival and proliferation during CORT stimulation. Interestingly, our results showed that CORT treatment itself could repress GCs.viability. The results thus suggested that CORT-induced unovulation might also be attributed to the developing failure of ovarian follicles caused by GCs damage.

\section{LHR transcriptional regulation}

The transcription of LHR is regulated by a variety of transcription factors [37, 38]. Previous studies have detected widespread distribution of AP1 in the follicular membrane and GCs within growing follicles and corpus luteum [39]. In the ovary, gonadotropins can induce a rapid and transient phosphorylation of the CREB protein in GCs, leading to the activation of transcription of many gonadotropin-regulated ovarian genes [40]. In the case of cell damage, AP1 cannot be activated, and the phosphorylation of CREB is also inhibited, resulting in the inability to activate gene transcription [41]. Considering that CORT might cause GCs damage as mentioned previously, we asked whether AP1 and CREB are involved in CORT-regulated LHR expression in GCs. Our in vivo and in vitro results both showed that CORT treatment reduced the levels of CREB, phosphorylated CREB (Ser133), c-Fos, and c-Jun in mouse ovarian GCs. In addition, the expression of LHR was suppressed when GCs were treated with inhibitors of AP1 and CREB, Therefore, our data suggested that the inhibitory effects of CORT on LHR expression might be dependent on the downregulation of AP1 and CREB in mouse ovarian GCs.

\section{Effect of GR on LHR transcription}

The feedback mechanism of hypothalamic-pituitary-adrenal axis involves the activation of glucocorticoids receptors (GR) by glucocorticoids [42]. GR belongs to the superfamily of ligand-induced transcription factors. After binding to corticosterone, these receptors are homodimerized or heterodimerized [43], and transferred to the nucleus to bind with other transcription factors or DNA response elements, leading to altered gene transcription [44-46]. However, there is no definitive evidence as to whether GR can specifically regulate LHR expression in GCs under stress conditions. Our in vivo and in vitro results showed that CORT activated GR expression in ovarian GCs, which was associated with decreased LHR expression. In contrast, inhibition of GR restored LHR expression in CORT-treated GCs. These data thus suggested that GR activation is required for CORT-repressed LHR expression.

GR can both positively or negatively regulate gene transcription by affecting the functions of transcription factors [47]. Therefore, under stress conditions, the CORT-GR axis might act through certain transcription factors to regulate LHR expression. Our results showed that the activation of GR reduced the expression of c-Fos, c-Jun, and CREB. In contrast, the GR inhibitor RU486 can block CORT-induced down-regulation of C-Fos, C-Jun, and CREB. These findings thus further demonstrated that CORT-mediated transcription regulation of LHR might depend on GR-induced suppression of AP1 and CREB. 


\section{Conclusion}

Taken together, our results showed a potential mechanism of stress-induced anovulation via inhibiting LHR expression through the CORT-GR-AP1/CREB signaling axis. Our results help to reveal the mechanism by which stress inhibits ovulation of animal follicles, and provides a theoretical basis for probing the cause of the decline in animal reproduction performance under stress. Therefore, developing small molecule inhibitors against this pathway might contribute to attenuate the undesirable effects of stress on reproductive performance in female animals.

\section{Abbreviations}

CORT: corticosterone; LH: luteinizing hormone; LHR: luteinizing hormone receptor; GC: granulosa cells; GR: glucocorticoid receptor.

\section{Declarations}

Ethics approval and consent to participate

All the animal experiments were performed in accordance with the guidelines of the Animal Research Institute Committee at Nanjing Agricultural University.

Consent for publication

Not applicable.

Availability of data and material

The datasets used and/or analyzed during the current study are available from the corresponding author on reasonable request.

Competing interests

The authors declare that they have no competing interests.

Funding

This work was supported by the National Natural Science Foundation of China (No. 31972571; No. 31630072; No. 31601939; No. 31972564), Program for the Top Young Talents in College of Animal Science and Technology at Nanjing Agricultural University (No. DKQB201903), the Fundamental Research Funds for the Central Universities (No. KJQN201705).

Author contributions 
Yinghui Wei was responsible for the research design, the performance of experiment, analysis of the data and drafting the manuscript. Ming Shen discussed the study and contributed significantly to manuscript writing. All listed authors have made substantial contributions to the research and its publication.

Acknowledgments

The authors wish to thank the editor and reviewers of Journal of Animal Science and Biotechnology for their valuable suggestions which have improved the manuscript.

\section{References}

1. Richards JS, Pangas SA. The ovary: basic biology and clinical implications. J Clin Invest. 2010;120:963-72.

2. Chen S, Liu X, Segaloff DL. A novel cyclic adenosine 3',5'-monophosphate-responsive element involved in the transcriptional regulation of the lutropin receptor gene in granulosa cells. Mol Endocrinol. 2000;14:1498-508.

3. Menon KM, Clouser CL, Nair AK. Gonadotropin receptors: role of post-translational modifications and post-transcriptional regulation. Endocrine. 2005;26:249-57.

4. Ubuka T, Tsutsui K. Reproductive neuroendocrinology of mammalian gonadotropin-inhibitory hormone. Reprod Med Biol. 2019;18:225-33.

5. Zeleznik AJ, Schuler HM, Reichert LE Jr. Gonadotropin-binding sites in the rhesus monkey ovary: role of the vasculature in the selective distribution of human chorionic gonadotropin to the preovulatory follicle. Endocrinology. 1981;109:356-62.

6. McFarland KC, Sprengel R, Phillips HS, Köhler M, Rosemblit N, Nikolics K, et al. Lutropinchoriogonadotropin receptor: an unusual member of the $\mathrm{G}$ protein-coupled receptor family. Science. 1989;245:494-9.

7. King SR, LaVoie HA. Gonadal transactivation of STARD1, CYP11A1 and HSD3B. Front Biosci (Landmark Ed). 2012;17:824-46.

8. Zhang FP, Poutanen M, Wilbertz J, Huhtaniemi I. Normal prenatal but arrested postnatal sexual development of luteinizing hormone receptor knockout (LuRKO) mice. Mol Endocrinol. 2001;15:17283.

9. Lei ZM, Mishra S, Zou W, Xu B, Foltz M, Li X, et al. Targeted disruption of luteinizing hormone/human chorionic gonadotropin receptor gene. Mol Endocrinol. 2001;15:184-200.

10. Valsamakis G, Chrousos G, Mastorakos G. Stress, female reproduction and pregnancy. Psychoneuroendocrinology. 2019;100:48-57.

11. Wagenmaker ER, Moenter SM. Exposure to Acute Psychosocial Stress Disrupts the Luteinizing Hormone Surge Independent of Estrous Cycle Alterations in Female Mice. Endocrinology. 2017;158:2593-602. 
12. Pierce BN, Hemsworth PH, Rivalland ET, Wagenmaker ER, Morrissey AD, Papargiris MM, et al. Psychosocial stress suppresses attractivity, proceptivity and pulsatile LH secretion in the ewe. Horm Behav. 2008;54:424-34.

13. Breen KM, Billings HJ, Wagenmaker ER, Wessinger EW, Karsch FJ. Endocrine basis for disruptive effects of cortisol on preovulatory events. Endocrinology. 2005;146:2107-15.

14. Wei Y, Li W, Meng X, Zhang L, Shen M, Liu H. Corticosterone Injection Impairs Follicular Development, Ovulation and Steroidogenesis Capacity in Mice Ovary. Animals (Basel). 2019;12:9.

15. Dobson H, Smith RF. What is stress, and how does it affect reproduction? Anim Reprod Sci. 2000;6061:743-52.

16. Phogat JB, Smith RF, Dobson $\mathrm{H}$. Effect of transport on pituitary responsiveness to exogenous pulsatile GnRH and oestradiol-induced LH release in intact ewes. J Reprod Fertil. 1999;116:9-18.

17. Breen KM, Karsch FJ. New insights regarding glucocorticoids, stress and gonadotropin suppression. Front Neuroendocrinol. 2006;27:233-45.

18. De Kloet ER, Meijer OC, de Nicola AF, de Rijk RH, Joëls M. Importance of the brain corticosteroid receptor balance in metaplasticity, cognitive performance and neuro-inflammation. Front Neuroendocrinol. 2018;49:124-45.

19. Mifsud KR, Reul J. Mineralocorticoid and glucocorticoid receptor-mediated control of genomic responses to stress in the brain. Stress. 2018;21:389-402.

20. Zhao F, Wu WJ, Wei QW, Zhao F, Wu W, Wei Q, Shen M, Li BJ, et al. Exogenous Adrenocorticotropic Hormone Affects Genome-Wide DNA Methylation and Transcriptome of Corpus Luteum in Sows [J]. FASEB Journal. 2019;33(3):3264-78.

21. Shen M, Jiang Y, Guan Z, Cao Y, Li L, Liu H, et al. Protective mechanism of FSH against oxidative damage in mouse ovarian granulosa cells by repressing autophagy. Autophagy. 2017;13:1364-85.

22. Shen M, Lin F, Zhang J, Tang Y, Chen WK, Liu H. Involvement of the up-regulated FoxO1 expression in follicular granulosa cell apoptosis induced by oxidative stress. J Biol Chem. 2012;287:25727-40.

23. Shen M, Jiang Y, Guan Z, Cao Y, Sun SC, Liu H. FSH protects mouse granulosa cells from oxidative damage by repressing mitophagy. Sci Rep. 2016;6:38090.

24. Shen M, Liu Z, Li B, Teng Y, Zhang J, Tang Y, Sun SC, Liu H. Involvement of FoxO1 in the effects of follicle-stimulating hormone on inhibition of apoptosis in mouse granulosa cells. Cell Death Dis. 2014;5:e1475.

25. Spencer RL, Deak T. A users guide to HPA axis research. Physiol Behav. 2017;178:43-65.

26. Miranda TB, Morris SA, Hager GL. Complex genomic interactions in the dynamic regulation of transcription by the glucocorticoid receptor. Mol Cell Endocrinol. 2013;380:16-24.

27. Joëls M, Baram TZ. The neuro-symphony of stress. Nat Rev Neurosci. 2009;10:459-66.

28. Magalhaes AC, Dunn H, Ferguson SS. Regulation of GPCR activity, trafficking and localization by GPCR-interacting proteins. Br J Pharmacol. 2012;165:1717-36. 
29. Miller BH, Takahashi JS. Central circadian control of female reproductive function. Front Endocrinol (Lausanne). 2013;4:195.

30. Robker RL, Hennebold JD, Russell DL. Coordination of Ovulation and Oocyte Maturation: A Good Egg at the Right Time. Endocrinology. 2018;159:3209-18.

31. Einarsson S, Brandt Y, Lundeheim N, Madej A. Stress and its influence on reproduction in pigs: a review. Acta Vet Scand. 2008;50:48.

32. Jeppesen JV, Kristensen SG, Nielsen ME, Humaidan P, Dal Canto M, Fadini R, et al. LH-receptor gene expression in human granulosa and cumulus cells from antral and preovulatory follicles. $\mathrm{J}$ Clin Endocrinol Metab. 2012;97:E1524-31.

33. De Kloet ER, Vreugdenhil E, Oitzl MS, Joëls M. Brain corticosteroid receptor balance in health and disease. Endocr Rev. 1998;19:269-301.

34. Takahashi M. Heat stress on reproductive function and fertility in mammals. Reprod Med Biol. 2012;11:37-47.

35. De Rensis F, Garcia-Ispierto I, López-Gatius F. Seasonal heat stress: Clinical implications and hormone treatments for the fertility of dairy cows. Theriogenology. 2015;84:659-66.

36. Zhu HS, Qian Z, Liu HL, Bao ED. ACTH-induced stress in weaned sows impairs LH receptor expression and steroidogenesis capacity in the ovary. Reprod Biol Endocrinol. 2016;14:80.

37. Peegel $H$, Towns R, Nair A, Menon KM. A novel mechanism for the modulation of luteinizing hormone receptor mRNA expression in the rat ovary. Mol Cell Endocrinol. 2005;233:65-72.

38. LaVoie HA. Transcriptional control of genes mediating ovarian follicular growth, differentiation, and steroidogenesis in pigs. Mol Reprod Dev. 2017;84:788-801.

39. Rusovici R, LaVoie HA. Expression and distribution of AP-1 transcription factors in the porcine ovary. Biol Reprod. 2003;69:64-74.

40. He PJ, Fujimoto Y, Yamauchi N, Hattori MA. Real-time monitoring of cAMP response element binding protein signaling in porcine granulosa cells modulated by ovarian factors. Mol Cell Biochem. 2006;290:177-84.

41. Kyriakis JM, Avruch J. Mammalian mitogen-activated protein kinase signal transduction pathways activated by stress and inflammation. Physiol Rev. 2001;81:807-69.

42. Chrousos GP, Kino T. Glucocorticoid signaling in the cell. Expanding clinical implications to complex human behavioral and somatic disorders. Ann N Y Acad Sci. 2009;1179:153-66.

43. Shyu AB, Belasco JG, Greenberg ME. Two distinct destabilizing elements in the c-fos message trigger deadenylation as a first step in rapid mRNA decay. Genes Dev. 1991;5:221-31.

44. Langlais D, Couture C, Balsalobre A, Drouin J. The Stat3/GR interaction code: predictive value of direct/indirect DNA recruitment for transcription outcome. Mol Cell. 2012;47:38-49.

45. Rao NA, McCalman MT, Moulos P, Francoijs KJ, Chatziioannou A, Kolisis FN, Alexis MN, Mitsiou DJ, Stunnenberg HG. Coactivation of GR and NFKB alters the repertoire of their binding sites and target genes. Genome Res. 2011;21:1404-16. 
46. Biddie SC, John S, Sabo PJ, Thurman RE, Johnson TA, Schiltz RL, Miranda TB, Sung MH, Trump S, Lightman SL, Vinson C, Stamatoyannopoulos JA, Hager GL. Transcription factor AP1 potentiates chromatin accessibility and glucocorticoid receptor binding. Mol Cell. 2011;43:145-55.

47. Kassel O, Schneider S, Heilbock C, Litfin M, Göttlicher M, Herrlich P. A nuclear isoform of the focal adhesion LIM-domain protein Trip6 integrates activating and repressing signals at AP-1- and NFkappaB-regulated promoters. Genes Dev. 2004;18:2518-28.

\section{Figures}



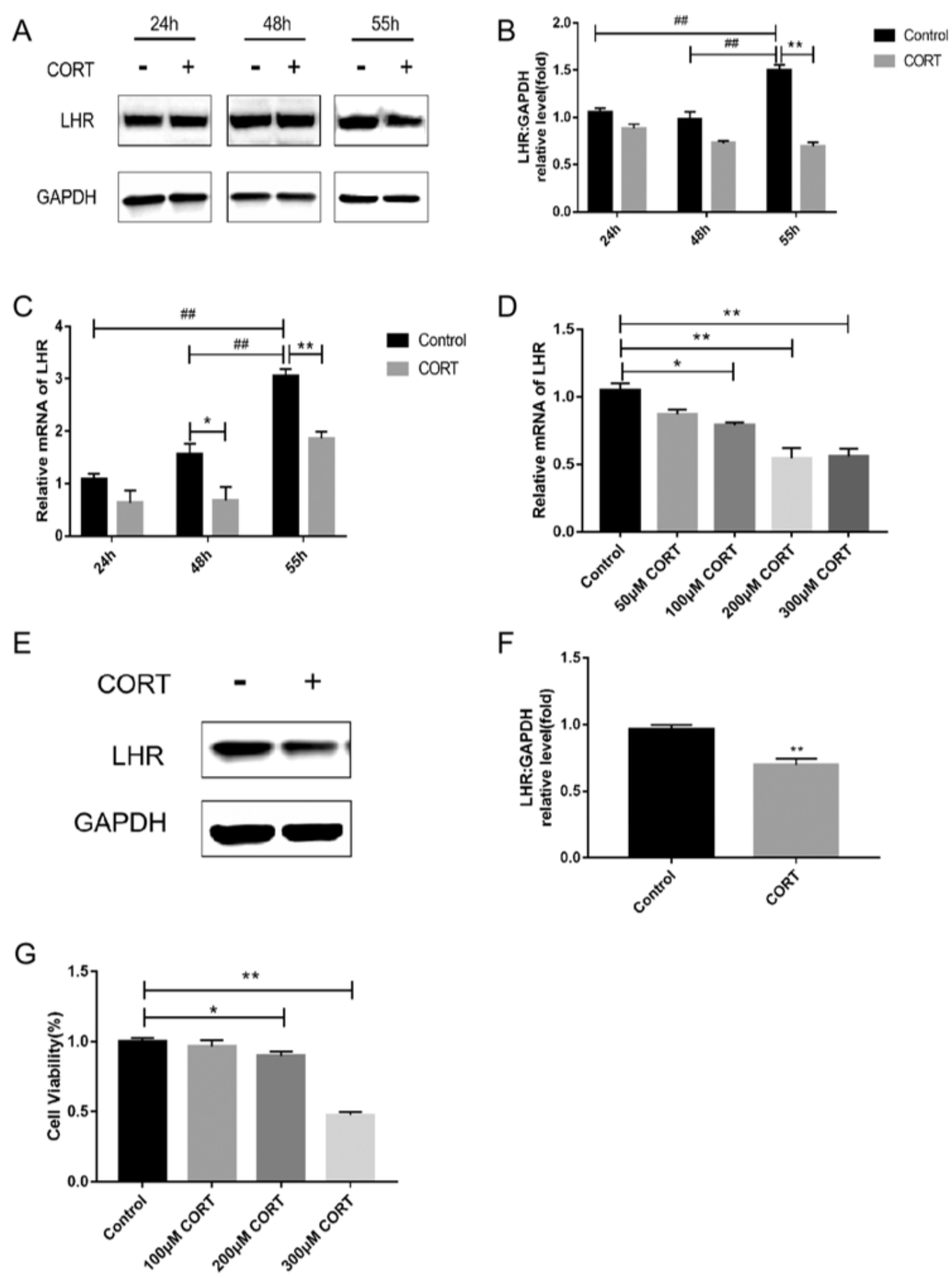

\section{Figure 1}

CORT inhibits LHR expression. (A) The expression of LHR in ovarian GCs of mice subjected to the indicated treatment was determined at $24 \mathrm{~h}, 48 \mathrm{~h}, 55 \mathrm{~h}$ after PMSG injection by Western blotting. (B) Quantification of LHR was performed using densitometric analysis. (C) The LHR in the ovarian GCs of the mice subjected to the designated treatment was measured by qRT-PCR at $24 \mathrm{~h}, 48 \mathrm{~h}, 55 \mathrm{~h}$ after PMSG injection. (D) The qRT-PCR assay of LHR mRNA levels in GCs with the indicated treatments. (E) Primary 
cultured GC was stimulated with CORT $(200 \mu \mathrm{M})$ for $12 \mathrm{~h}$. Expression levels of LHR in GCs were determined using western blotting. (F) Quantification of LHR protein levels was performed using densitometric analysis. (G) Treated primary cultured GCs with different concentrations ( $100 \mu \mathrm{M}$ to $300 \mu \mathrm{M})$ of CORT for $12 \mathrm{~h}$, and then use the CCK-8 assay to determine cell viability. Data are shown as mean $\pm \mathrm{S}$. $E . ; n=3 . *, P<0.05 ; * * ; P<0.01$. \#, $P<0.05 ; \# \#, P<0.01$ compared to 55 h-control group.

A

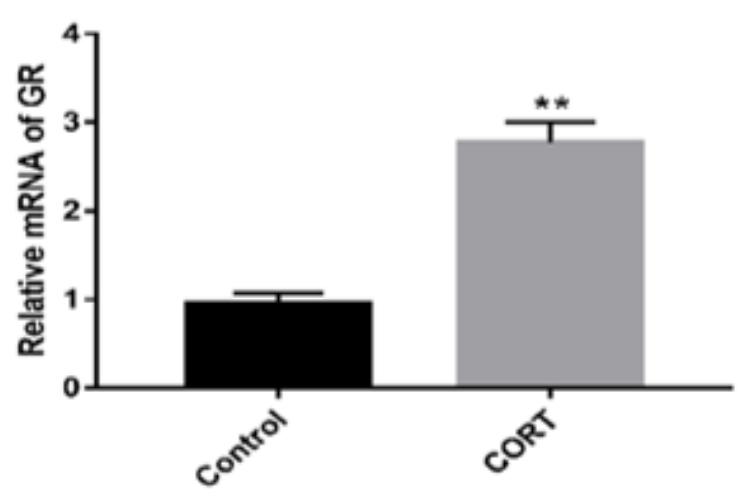

C

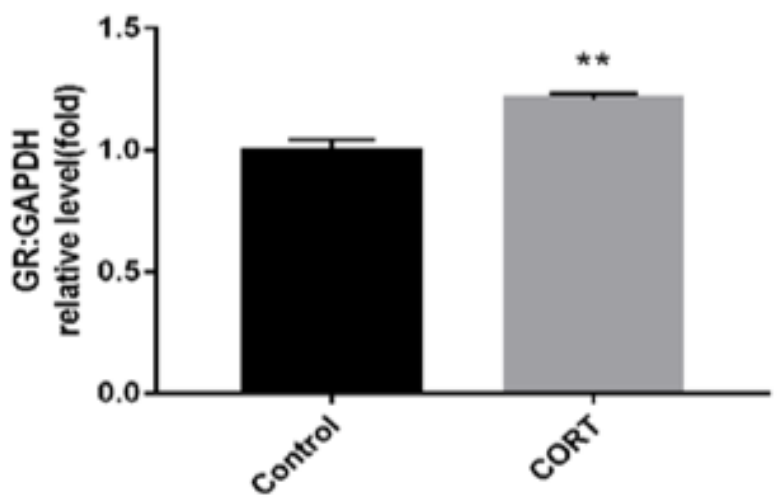

$E$

B

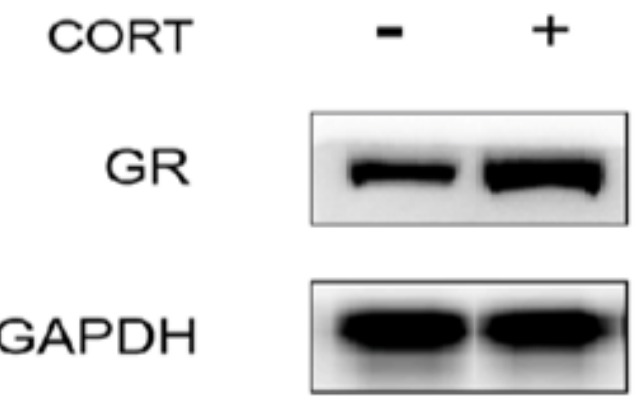

D

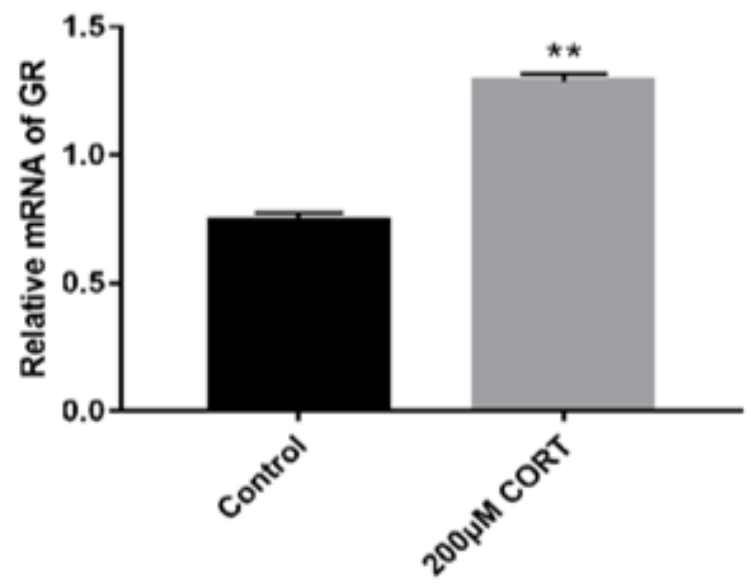

GR

GAPDH

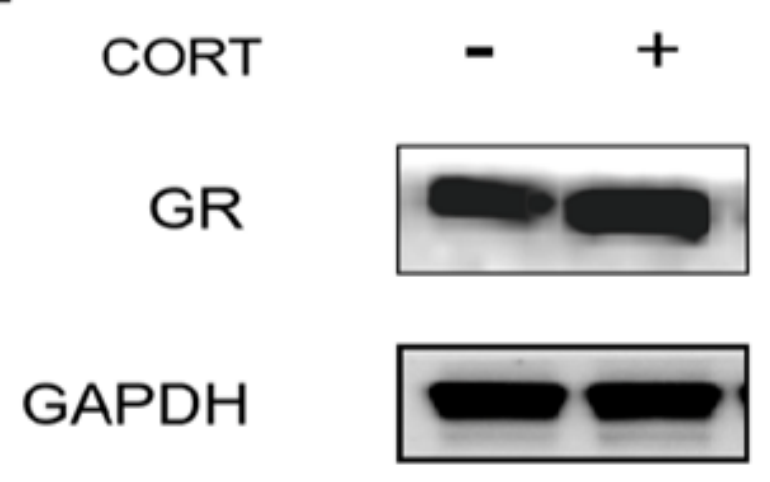

F

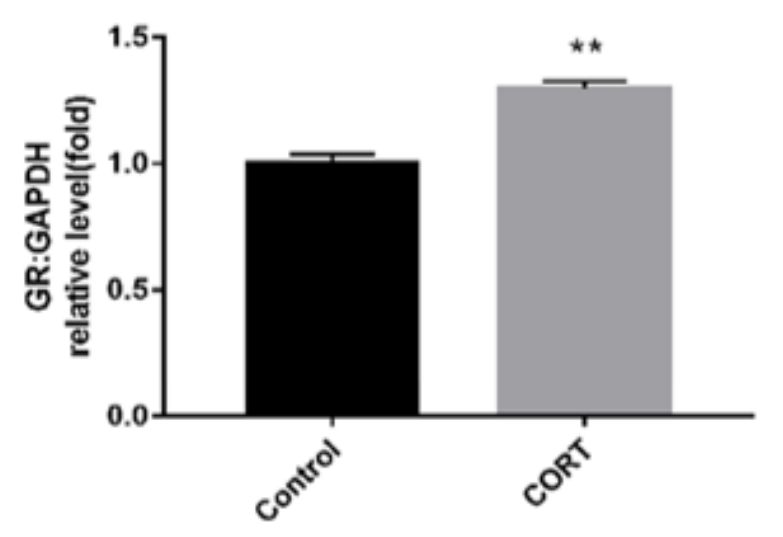

Figure 2 
CORT activates GR expression. (A) At $55 \mathrm{~h}$ after PMSG injection, mouse ovarian GCs were collected from the control group and the CORT injection group to detect the GR expression by qRT-PCR and (B) western Blot; (C) The protein levels of GR were quantified using densitometric analysis; (D-E) Primary cultured ovarian GCs were treated with CORT $(200 \mu \mathrm{M})$ for 12 hours, and (D) collected for qRT-PCR or (E) western Blotting assay of GR expression; $(F)$ The protein levels of GR were quantified using densitometric analysis. Data are shown as mean $\pm S$. $E . ; n=3$. * $P<0.05 ; * \star, P<0.01$.
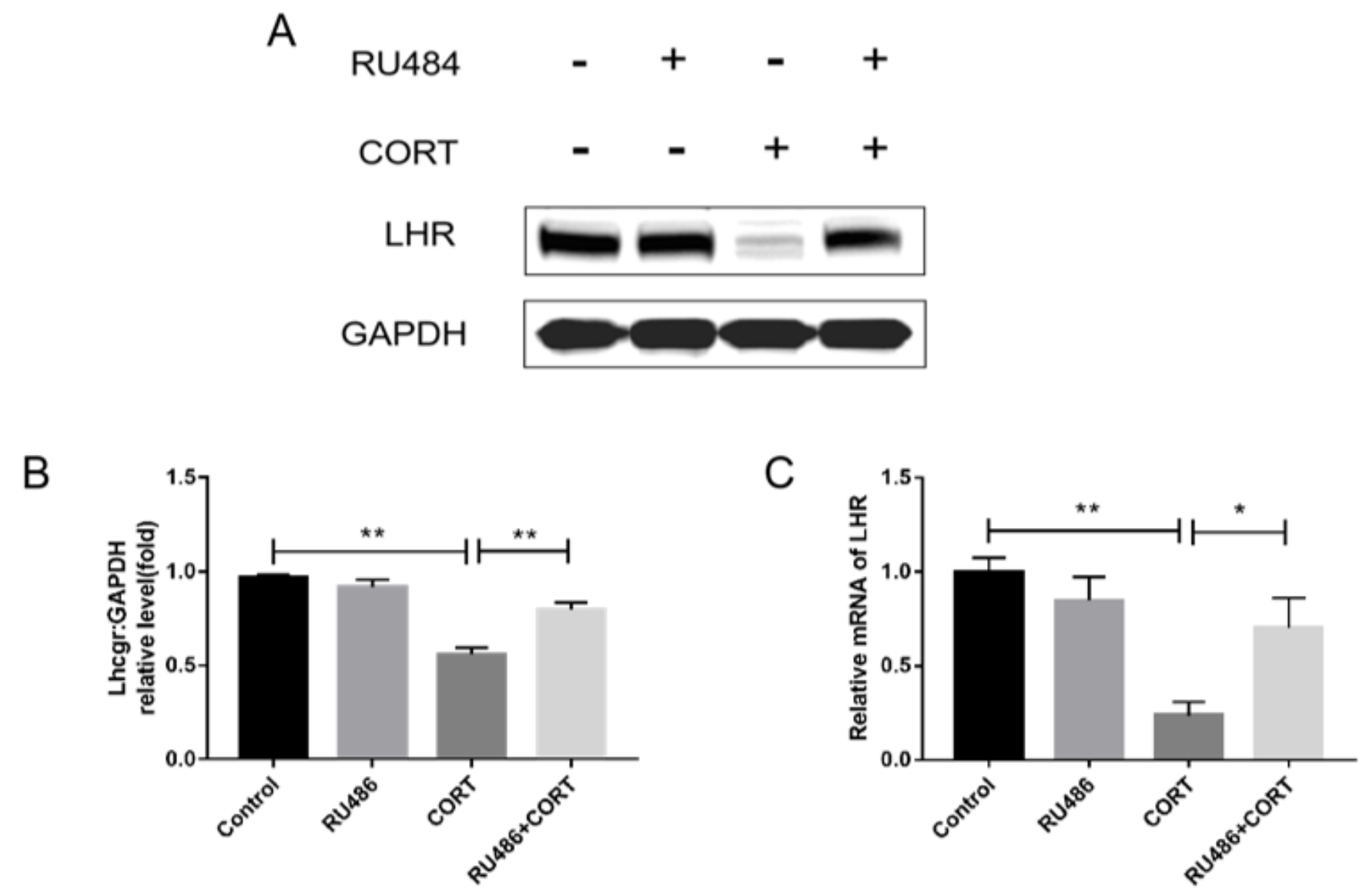

\section{Figure 3}

GR is required for CORT-induced suppression of LHR expression. (A-C) Primary cultured ovarian GCs were incubated with GR inhibitor RU486 $(50 \mu \mathrm{M})$ for $2 \mathrm{~h}$. (A) GCs were cultured with or without CORT $(200 \mu \mathrm{M})$ for $12 \mathrm{~h}$, and then collected for qRT-PCR assay to detect LHR mRNA Expression; (B) The expression of LHR protein was detected by Western Blot, and (C) the protein levels of GR were quantified using densitometric analysis. Data are shown as mean $\pm \mathrm{S}$. $\mathrm{E}$; $\mathrm{n}=3$. ${ }^{*}, \mathrm{P}<0.05 ;{ }^{\star *}, \mathrm{P}<0.01$. 
A

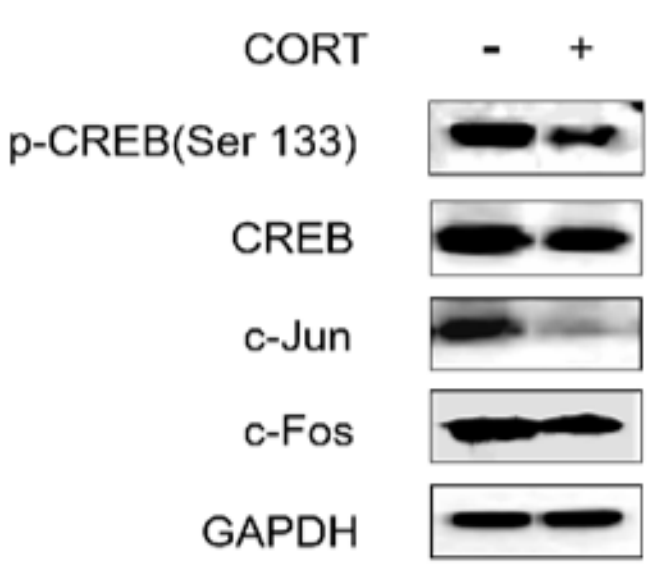

B

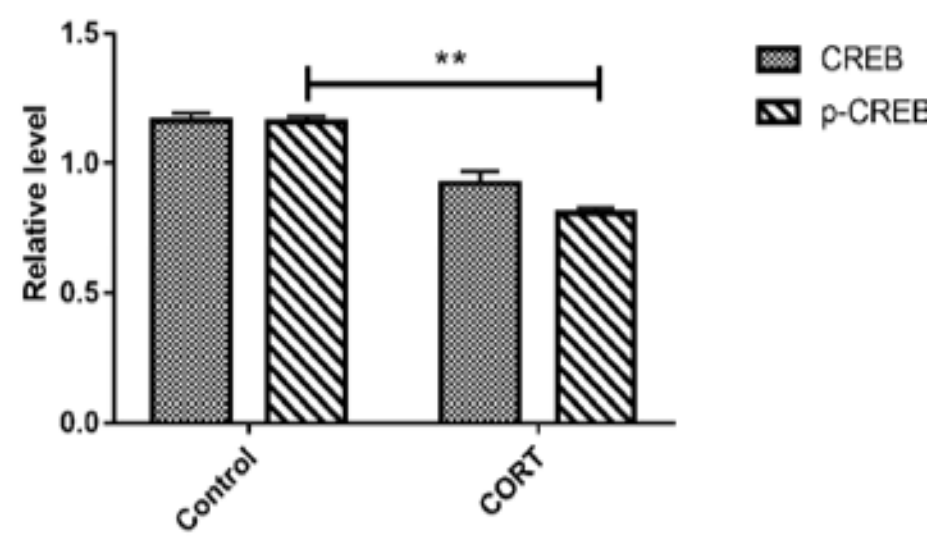

C
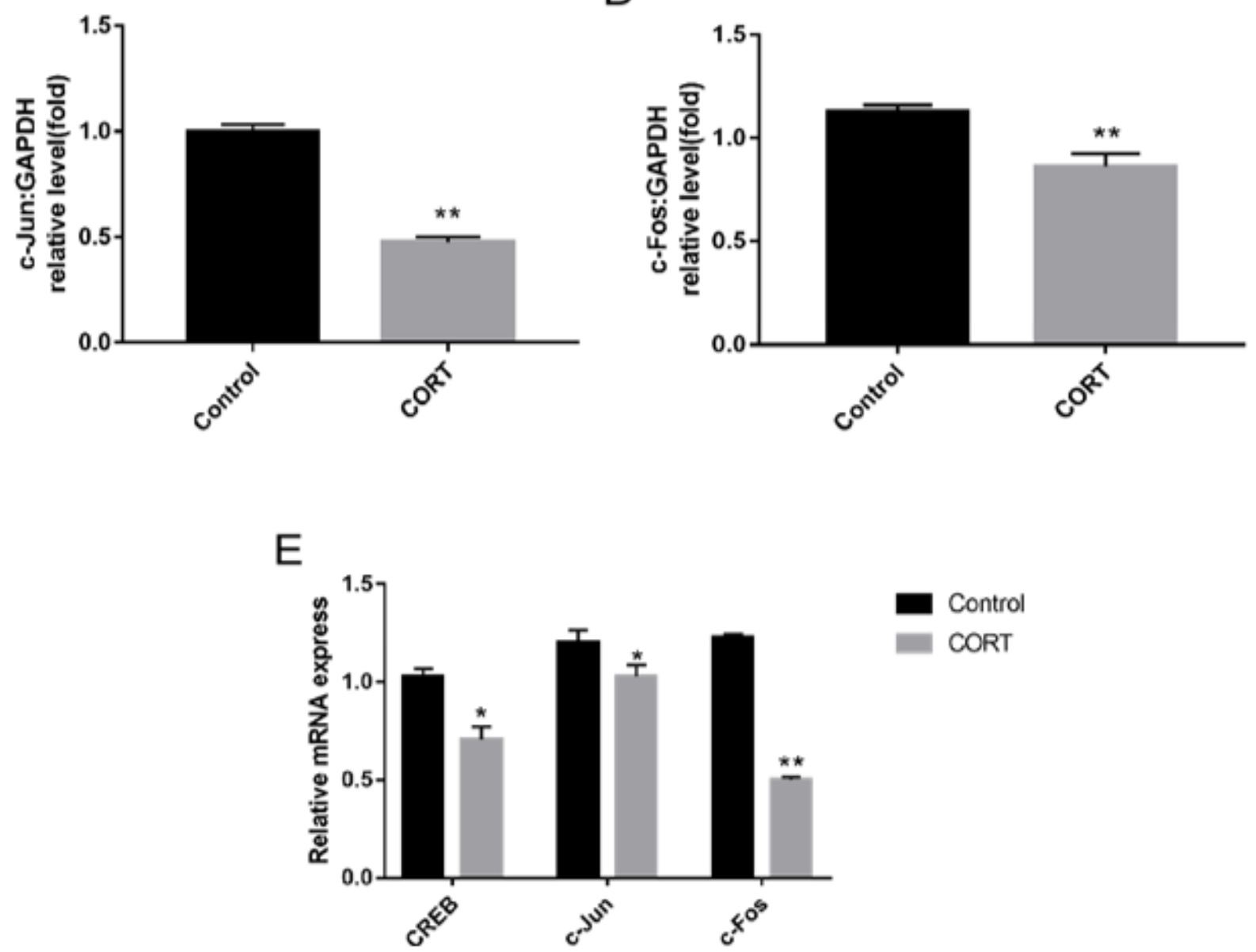

Figure 4

CORT injection reduces AP1 and CREB expression in vivo. (A-D) At $55 \mathrm{~h}$ after PMSG injection, mouse ovarian GCs were collected from the control group and the CORT injection group, and the expressions of CREB and p-CREB, c-Jun, and c-Fos proteins were detected by Western blot analysis. The protein bands were quantified using densitometric analysis. GAPDH served as the control for loading. (E) The mRNA 
levels of c-Fos, c-Jun and CREB in ovarian granulosa cells were determined by qRT-PCR. Data are shown as mean \pm S. E.; $n=3$. *, $\mathrm{P}<0.05 ; * \star, P<0.01$.



B
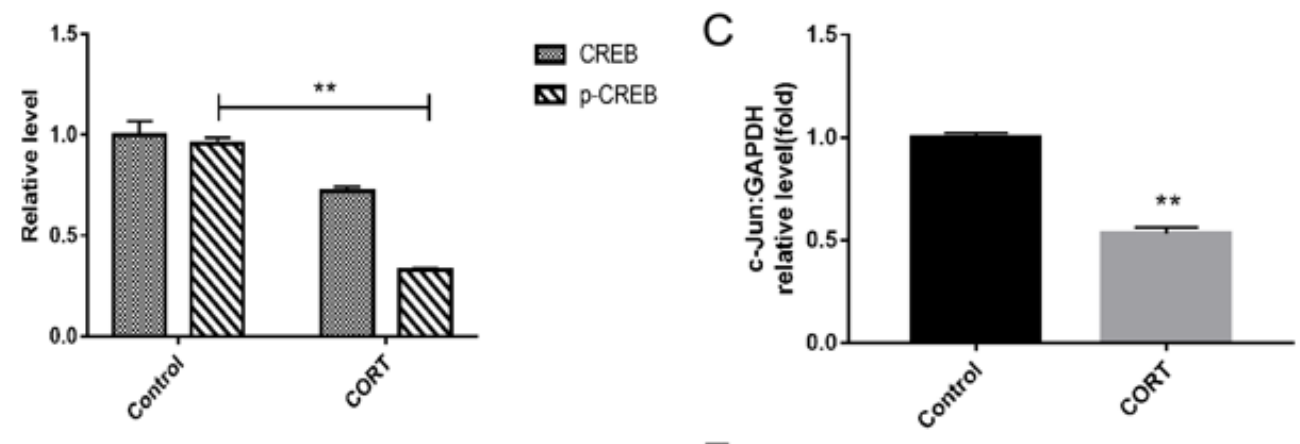

$\mathrm{D}$

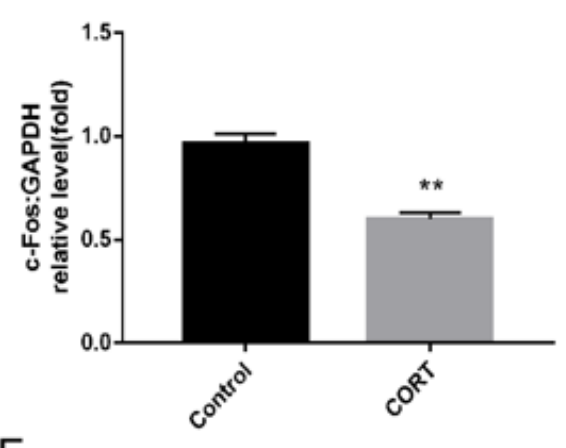

$\mathrm{F}$

$E$
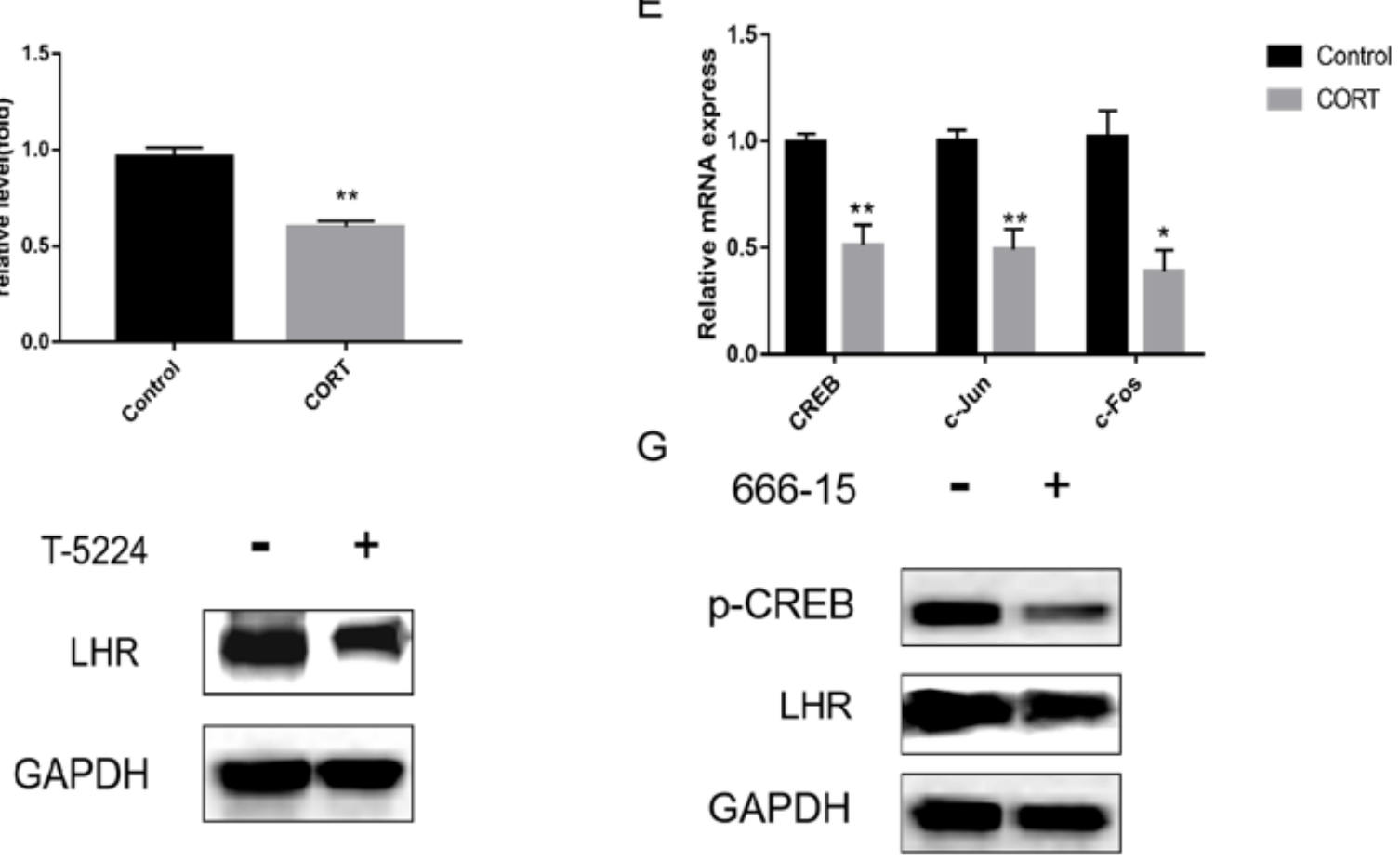

Figure 5

CORT inhibits the expression of AP1 and CREB in cultured GCs. (A-D) GCs were treated with or without CORT $(200 \mu \mathrm{M})$ for $12 \mathrm{~h}$, then the expressions of CREB, p-CREB, c-Jun, and c-Fos proteins were detected by Western blot analysis. The protein bands were quantified using densitometric analysis. GAPDH served 
as the control for loading. (E) The mRNA levels of c-Fos, c-Jun and CREB in ovarian GCs were determined by qRT-PCR. (F-G) Primary cultured ovarian GCs were treated with AP1 inhibitor T-5224 $(75 \mu \mathrm{M})$ and CREB inhibitor 666-15 $(7.5 \mu \mathrm{M})$ for $24 \mathrm{~h}$. Expression levels of LHR in ovarian granulosa cells were determined using western blotting.

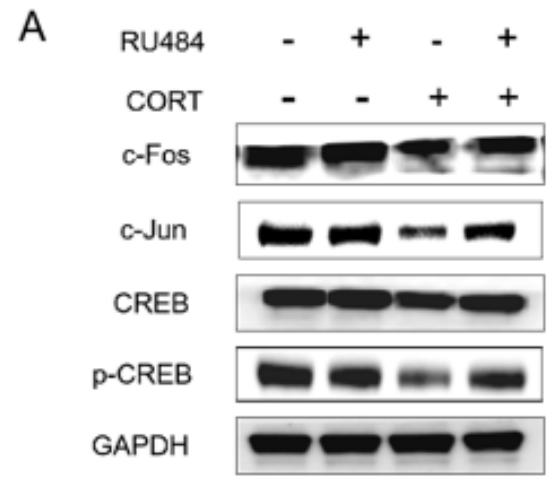

B

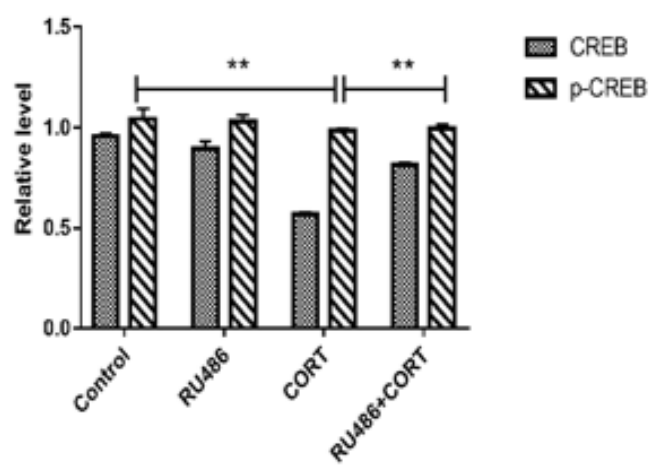

C
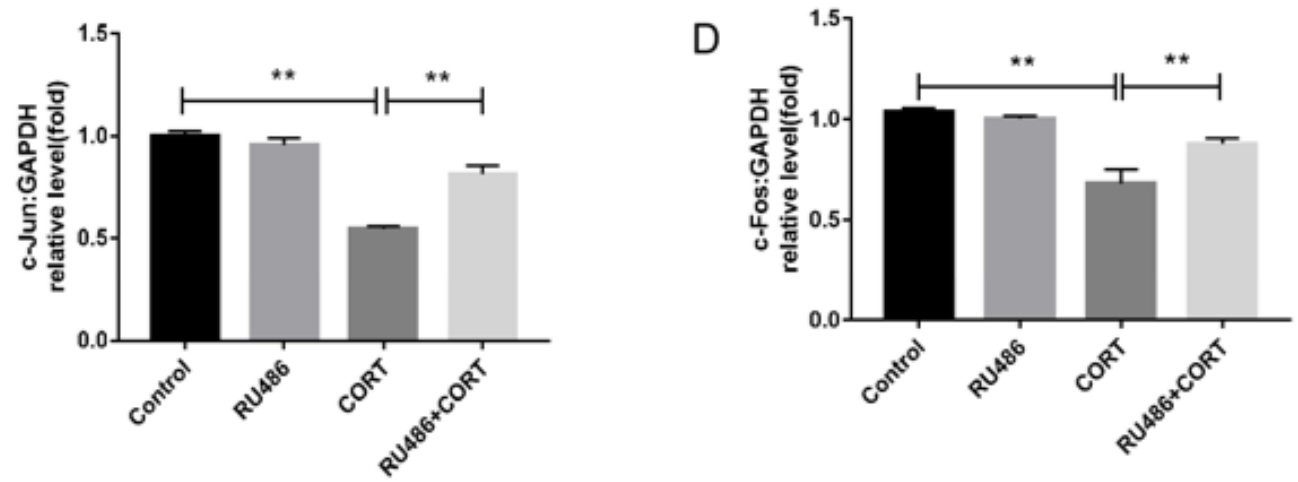

E

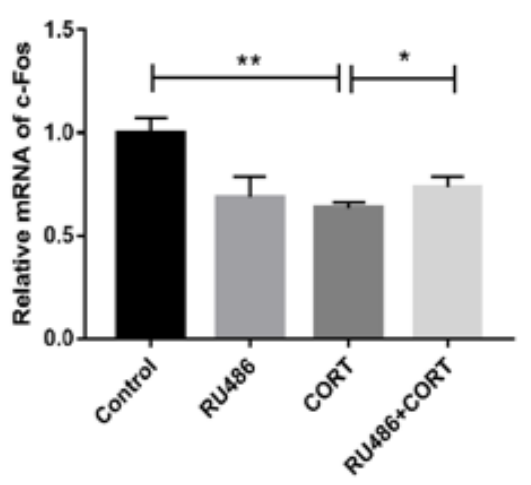

$\mathrm{F}$

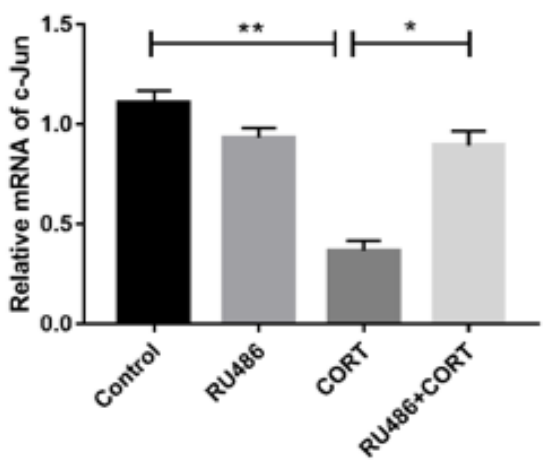

G

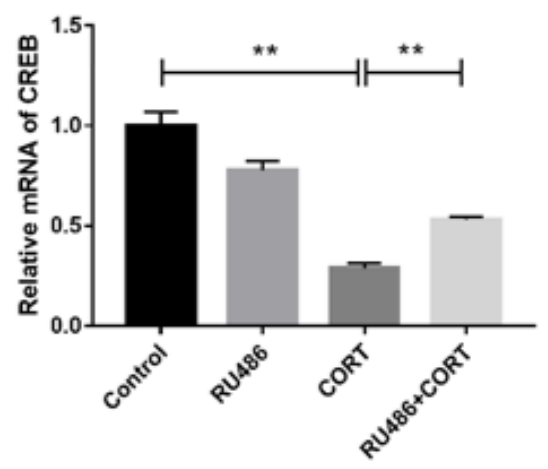

\section{Figure 6}

The expression of AP1 and CREB is regulated by GR. Primary cultured GCs were incubated with CORT $(200 \mu \mathrm{M})$ for $12 \mathrm{~h}$. GR inhibitor RU486 $(50 \mu \mathrm{M})$ was added $2 \mathrm{~h}$ before CORT treatment. (A-D) The levels of CREB, p-CREB, c-Jun, and c-Fos proteins were detected by Western blot analysis. The protein bands were quantified using densitometric analysis. GAPDH served as the control for loading. (E-G) The expression levels of c-Fos, c-Jun and CREB in GCs were measured by qRT-PCR. Data are shown as mean $\pm \mathrm{S}$. E.; $n=$ 3. *, $\mathrm{P}<0.05 ; * \star, \mathrm{P}<0.01$. 